\title{
Role of selenium and zinc in the pathogenesis of food allergy in infants and young children
}

\author{
Barbara Kamer ${ }^{1}$, Wojciech Wąsowicz², Konrad Pyziak ${ }^{1}$, Anna Kamer-Bartosińska ${ }^{3}$, \\ Jolanta Gromadzińska², Renata Pasowska ${ }^{1}$
}

\author{
12 ${ }^{\text {nd }}$ Department of Paediatrics and Allergology, Polish Mother's Memorial Hospital - \\ Research Institute, Lodz, Poland \\ 2Department of Toxicology and Carcinogenesis, Institute of Occupational Medicine, \\ Lodz, Poland \\ ${ }^{3}$ Department of Operative Gynecology, Polish Mother's Memorial Hospital - \\ Research Institute, Lodz, Poland
}

Submitted: 8 December 2010

Accepted: 21 April 2011

Arch Med Sci 2012; 8, 6: 1083-1088

DOI: 10.5114 /aoms.2012.32420

Copyright (c) 2012 Termedia \& Banach

\author{
Corresponding author: \\ Prof. Barbara Kamer \\ $2^{\text {nd }}$ Department of Pediatrics \\ and Allergology \\ Polish Mother's \\ Memorial Hospital \\ - Research Institute \\ 281/189 Rzgowska St \\ 93-338 Lodz, Poland \\ Phone: +48 422712091 \\ Fax: +48 422711386 \\ E-mail: sek41@iczmp.edu.pl
}

\begin{abstract}
Introduction: Selenium and zinc are indispensable microelements for normal functioning and development of the human body. They are cofactors of many enzymes of the antioxidative barrier (selenium - glutathione peroxidase; zinc - superoxide dismutase). The aim of the study was to evaluate the importance of selenium and zinc in the pathogenesis of food allergy in small children.

Material and methods: The study was performed in 134 children with food allergy, aged 1 to 36 months. The control group was composed of 36 children at the same age, without clinical symptoms of food intolerance. Each child had estimated serum levels of zinc and selenium. Furthermore, the authors evaluated activity of glutathione peroxidase (GSH-Px) in erythrocyte lysates and serum. Tests were performed twice, before and after 6-month administration of elimination diet.

Results: The obtained results showed that children with food allergy had significantly lower concentrations of selenium, zinc and examined enzymes in comparison to children from the control group. Concentration of selenium and zinc as well as activity of examined enzymes increased after application of eliminative diet.

Conclusions: In children with allergy decreased concentrations of selenium and zinc, and lower values of glutathione peroxidase and superoxide dismutase which increased after elimination diet were affirmed. These observations suggest their role in pathogenesis of food allergy. Conducted observations indicate the need to monitor trace elements content in the diet in children with food allergy. The results showed that children with food allergy had a weakened antioxidative barrier.
\end{abstract}

Key words: selenium, zinc, food allergy, small children.

\section{Introduction}

Selenium (Se) and zinc (Zn) are important and indispensable trace elements for normal functioning of the human body, especially during intensified growth. They show multidirectional biological activity. They are cofactors of antioxidative enzymes being an integral part of their molecule. The Se bound by cysteine is found mostly in cytosol and is a part of glutathione peroxidase (GSH-Px), which catalyses disintegration of hydrogen 
peroxide and modifies lipid hydroxides to harmless molecules (water and proper metals). Zinc is a cofactor of many enzymes including superoxide dismutase (SOD) [1-5].

Glutathione peroxidase and superoxide dismutase play an important role in maintaining the oxidative-antioxidative balance. Disturbance of this balance leads to the attack of reactive oxygen species (ROS) and damage of the cell membrane. As the result of this reaction, thiobarbituric acid reactive substances (TBARS) are formed. Their value informs about the degree of cell membrane damage caused by ROS [1, 6-10].

In the literature, the participation of ROS in etiopathogenesis of many pathological states, including heart diseases, neoplasms, rheumatoid arthritis, the aging process, peptic ulcer disease and ulcerative colitis, allergic diseases and many others, is emphasized [7, 11-16].

Food allergy seems to be an important current clinical problem, especially in younger children. Its frequency is estimated from $1.8 \%$ to $10 \%$ of the paediatric population and is highest during the first three years of life $[17,18]$. The pathogenesis of allergy is still not completely known. Its diverse symptoms are observed after food consumption, and are based on different immunological mechanisms of 4 types of allergy according to Gell and Coombs [19]. Children with food hypersensitivity have increased amounts of mastocytes, eosinophils and neutrophils in the digestive tract $[20,21]$. Persistent exposure to allergen can lead to chronic inflammatory changes of mucous membrane and increased production of ROS. Excess ROS should be neutralized by components of the antioxidative barrier. Therefore all disturbances of enzymatic and non-enzymatic mechanisms of this barrier lead to many unfavourable reactions including oxidation of cell membrane lipids [7, 22-25].

Participation of ROS in the pathogenesis of allergic diseases is quite often emphasized in the literature $[4,14,15,20,21,24,26]$. Still there are few studies concerning the role of Se and $\mathrm{Zn}$ in the pathogenesis of food allergy $[24,27]$ but more concerning Se concentrations in children with bronchial asthma [4, 28-30] and the results are ambiguous. Moreover, Se has an influence on the endocrine system and immunity mechanisms. Similarly, Zn plays a role in normal reactions of the immune system (both humoral and cellular) of a child [31-33].

The aim of the study was to investigate and to assess the role of Se and $\mathrm{Zn}$ in the pathogenesis of food allergy in infants and young children.

\section{Material and methods}

The study was performed in 134 children including 49 girls (36.6\%) and 85 boys (63.4\%) with food allergy, treated in the $2^{\text {nd }}$ Department of Paediatrics and Allergology and afterwards in the Outpatient Department of Allergology, in the Polish Mother's Memorial Hospital Research Institute. The age of examined children ranged from 1 to 36 months (mean age: 15.4 months) including 68 infants (50.7\%), 43 children in the second year of life (32.1\%) and 23 children in the third year of life (17.2\%). The control group comprised 36 healthy children including 16 girls (44.4\%) and 20 boys (55.6\%) at the same age, without clinical symptoms of food intolerance. The analysis of sex in both groups showed significant predominance of boys.

The diagnosis of food allergy was established by medical history including positive family history for food allergy and type of child feeding, presence of clinical symptoms, elimination-provocation challenge and estimation of serum levels of allergenspecific IgE (RAST) by the immunochemical method. Results below $0.02 \mathrm{IU} / \mathrm{ml}$ were regarded as lack of atopy, while serum concentration $\geq 0.76 \mathrm{IU} / \mathrm{ml}$ ( $\geq 2^{\text {nd }}$ class of atopy classification) [34] was regarded as incorrect. Proteins of cow milk, soy, fish, poultry, pork, beef, yolk and white of egg, carrot and tomato were taken into consideration.

Whole blood samples were collected using a technique for Se by fluorimetry and for Zn by flame atomic absorption spectrophotometry [35]. In addition, the authors evaluated activity of glutathione peroxidase (GSH-Px) in erythrocyte lysates and serum (by the method of Paglia and Valentine) [36], and superoxide dismutase (SOD) (by the method of Minami and Yoshikawa) [37]. Tests were performed twice, before and after 6-month administration of the elimination diet.

For conducting the study formal consent of parents and approval of the Ethics Committee were obtained.

\section{Statistical analysis}

Results of the study were statistically analysed using the statistical package CSS Statistica. For continuous features arithmetic mean $(x)$ and standard deviation (SD) were calculated. Normality of decomposition was investigated by the Shapiro Wilk test $(p=0.05)$. For comparison of average values Student's $t$-test or Mann-Whitney U-test was used. Dependences between features were calculated using the coefficient of correlation by Pearson or Spearman. Also the coefficient of regression equation was calculated.

For conducting the study formal consent of parents and approval of the Ethics Committee were obtained.

\section{Results}

The obtained results showed that among 134 children with food allergy, significantly more children (94 children - 70.1\%) had a positive fami- 
ly history for allergy in comparison to children from the control group (3 children - 8.3\%) $(p<0.05)$. Analysis of feeding showed that among patients with allergy, 46 children (34.3\%) were fed artificially from birth in comparison to 6 children from the control group (16.7\%). The difference was statistically significant $(p<0.05)$. It should be noted that the percentage of children breast fed longer than 6 months was significantly lower in children with food allergy (27 children - 20.2\%) in comparison to children from the control group (14 children $-38.9 \%)$.

The analysis of the results showed that among 134 children with food allergy, 91 children (67.9\%) had IgE-dependent allergy (allergen-specific IgE against) against chosen food allergens $\geq 2^{\text {nd }}$ class) while 43 children had IgE-independent allergy. In both groups the most frequent allergens were proteins of cow milk $(62.6 \%)$ followed by yolk of egg (16.5\%), soya (14.3\%) and white of egg (12.1\%). Analysis of feeding type during infancy showed that the percentage of children artificially fed was higher among children with food allergy (34.3\%) in comparison to children from the control group (16.7\%).

Analysis of clinical manifestation of food allergy in the examined children showed that only 43 children $(32.1 \%)$ had an isolated form of allergy (presenting symptoms from only one system). On the other hand, significantly more children (91 patients -67.9\%) had symptoms from at least two systems. Analysis of symptoms from particular systems showed that 99 children (73.9\%) presented symp- toms from the respiratory tract and 96 children (71.6\%) had symptoms from the digestive tract, while 76 children (56.7\%) had skin changes.

Children with food allergy (both IgE-dependent and IgE-independent) had significantly lower blood concentrations of Se before dietary treatment in comparison to children from the control group. Children with IgE-dependent allergy had higher blood concentrations of Se in comparison to children with IgE-independent allergy. Similarly, serum concentrations of $\mathrm{Zn}$ were lower in children with both types of allergy in comparison to children without allergy, and this difference was statistically significant. Mean concentrations of examined microelements increased after dietary treatment (Table I).

The analysis of activity of examined enzymes (GSH-Px and SOD) showed that mean values were significantly lower in children with IgE-dependent allergy in comparison to the control group. Similarly, children with IgE-independent food reactions had lower mean values of glutathione peroxidase activity in erythrocytes as well as serum superoxide dismutase concentrations. On the other hand, there were no such differences concerning serum activity of glutathione peroxidase. Activity of examined enzymes increased after application of an eliminative diet and this dependence was stronger in the case of serum levels of glutathione peroxidase (Table II).

The percentage decrease of examined enzymes in children with allergy in comparison to children without allergy is graphically shown in Figure 1.

Table I. Mean values of selenium (Se) and zinc (Zn)

\begin{tabular}{|lcccccc|}
\hline Microelements & Tests & \multicolumn{5}{c|}{ Examined children } \\
\cline { 2 - 4 } & & $\begin{array}{c}\text { IgE-dependent } \\
\text { food allergy }\end{array}$ & $\begin{array}{c}\text { Significance } \\
\text { of differences }\end{array}$ & $\begin{array}{c}\text { Control } \\
\text { group }\end{array}$ & $\begin{array}{c}\text { Significance } \\
\text { of differences }\end{array}$ & $\begin{array}{c}\text { IgE-independent } \\
\text { food reactions }\end{array}$ \\
\hline Se $[\mu \mathrm{g} / \mathrm{l}]$ & $\mathrm{I}$ & $42.6 \pm 15.4$ & $p<0.05$ & $48.3 \pm 10.5$ & $p<0.02$ & $39.2 \pm 10.6$ \\
\cline { 2 - 5 } & $\mathrm{II}$ & $45.6 \pm 14.5$ & $p>0.05$ & & $p<0.05$ & $40.1 \pm 9.1$ \\
\hline Zn $[\mathrm{mg} / \mathrm{l}]$ & $\mathrm{I}$ & $0.81 \pm 0.3$ & $p<0.05$ & $0.85 \pm 0.26$ & $p<0.05$ & $0.72 \pm 0.15$ \\
\cline { 2 - 4 } & II & $0.87 \pm 0.88$ & $p>0.05$ & & $p>0.05$ & $0.77 \pm 0.18$ \\
\hline
\end{tabular}

I- before, 11 - after at least 6 months of treatment

Table II. Mean values of GSH-Px and SOD activity in examined children

\begin{tabular}{|c|c|c|c|c|c|c|}
\hline \multirow[t]{2}{*}{ Microelements } & \multirow[t]{2}{*}{ Tests } & \multicolumn{5}{|c|}{ Examined children } \\
\hline & & $\begin{array}{l}\text { IgE-dependent } \\
\text { food allergy }\end{array}$ & $\begin{array}{l}\text { Significance } \\
\text { of differences }\end{array}$ & $\begin{array}{l}\text { Control } \\
\text { group }\end{array}$ & $\begin{array}{l}\text { Significance } \\
\text { of differences }\end{array}$ & $\begin{array}{l}\text { IgE-independent } \\
\text { food reactions }\end{array}$ \\
\hline \multirow{2}{*}{$\begin{array}{l}\text { GSH-Pxo } \\
{[\text { j.e. } / \mathrm{ml}]}\end{array}$} & 1 & $0.11 \pm 0.04$ & $p<0.08$ & \multirow[t]{2}{*}{$0.13 \pm 0.04$} & $p>0.05$ & $0.13 \pm 0.07$ \\
\hline & II & $0.23 \pm 0.25$ & $p<0.05$ & & $p>0.05$ & $0.15 \pm 0.04$ \\
\hline \multirow{2}{*}{$\begin{array}{l}\text { GSH-Pxe } \\
\text { [j.e./gHb] }\end{array}$} & 1 & $10.4 \pm 2.9$ & $p<0.05$ & \multirow[t]{2}{*}{$11.8 \pm 2.9$} & $p<0.05$ & $10.5 \pm 2.9$ \\
\hline & II & $11.2 \pm 2.4$ & $p>0.05$ & & $p>0.05$ & $11.8 \pm 4.8$ \\
\hline \multirow[t]{2}{*}{$\mathrm{SOD}[\mathrm{U} / \mathrm{mgHb}]$} & 1 & $1.25 \pm 0.45$ & $p<0.05$ & \multirow[t]{2}{*}{$1.67 \pm 0.66$} & $p<0.05$ & $1.40 \pm 0.30$ \\
\hline & ॥ & $1.62 \pm 0.67$ & $p>0.05$ & & $p>0.05$ & $1.60 \pm 0.63$ \\
\hline
\end{tabular}

I- before, 11 - after at least 6 months of treatment 
A

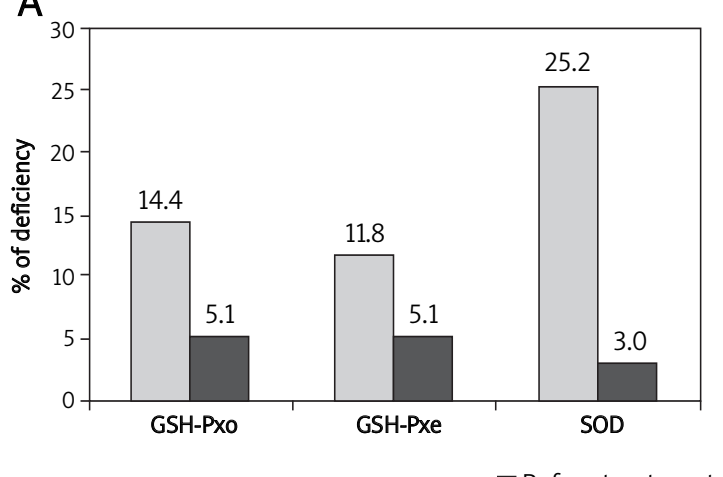

B

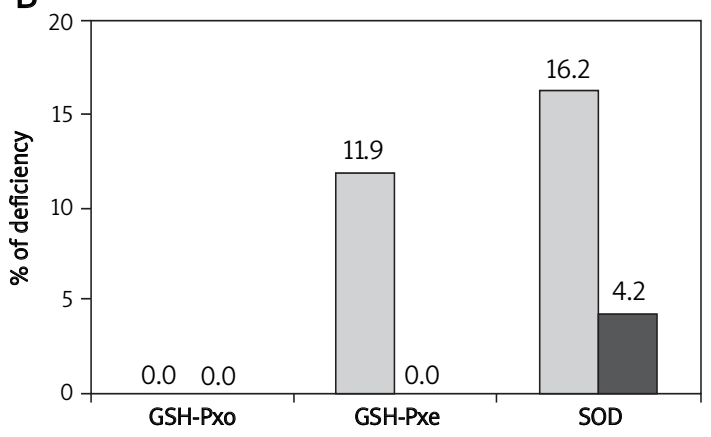

After treatment

Figure 1. Analysis of deficiencies of examined enzymes before and after treatment

A

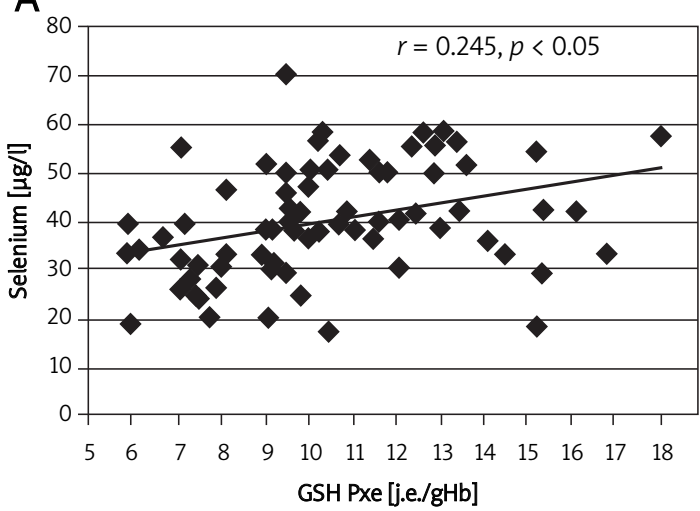

B

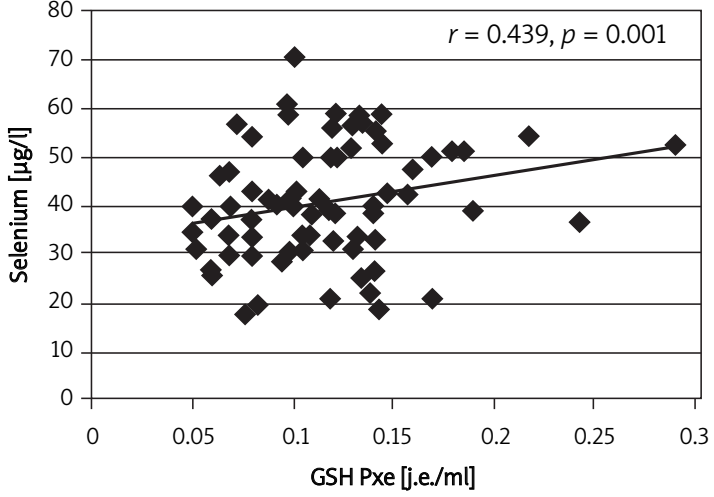

Figure 2. Correlation between concentrations of selenium (Se) and glutathione peroxidase (GSH-Px) of examined children

Results of the analysis also showed a positive correlation between activity of glutathione peroxidase and Se serum concentrations. Results of Spearman's correlation coefficient in children with both types of allergy are graphically shown in Figure 2.

A significant positive correlation between both serum and erythrocyte activity of glutathione peroxidase and Se concentrations was found. On the other hand, no correlation was found between activity of superoxide dismutase and Zn concentrations. Spearman's correlation coefficient was not significant $(r=0.197, p=0.08)$.

\section{Discussion}

Selenium and Zn play many significant functions in the human body, including an important role in the antioxidative barrier, because of their participation in the active centre of purification system enzymes. In the present study, children with food allergy (both IgE-dependent and IgE-independent) had significantly lower values of Se and $\mathrm{Zn}$ in comparison to examined children without allergy. These findings are compatible with the results of other authors [24, 27]. Similarly, some authors confirmed lower Se concentrations in children with bronchial asthma [4, 15, 28, 29] and atopic dermatitis [30]. Deficiency of these elements can be a cause of decreased activity of glutathione peroxidase and superoxide dismutase [7, 24, 38].

It should be mentioned that decrease of Se and Zn concentrations can be caused by many factors, including supply in the diet, capacity for absorption in the digestive tract, and age of the child. Blood concentration of Se depends on diet and content in soil [39-41]. The study of Wąsowicz and Zachara published in 1987 [42] and the study of Zachara published in 1983 [43] showed that Poland is one of the countries that have soil poor in Se. Daily consumption of this element is low, which causes its decreasing amount in mother's milk during lactation [44]. Similar dependence was shown in the Greek population by Bratakos and loannou in 1991 [45]. Taking into consideration the fact that milk is an essential food for infants and small children, it seems that the supply of Se in children is insufficient. On the other hand, the requirements of a child are high because of age and the quick rate of somatic growth [5, 37].

Another possible cause of Se deficiency in small children with food allergy is the still immature or 
defective function of the small intestine mucous membrane, causing decreased absorption. Confirmation of this thesis can be found in the study of Aaseth et al. [46], who observed a considerable decrease of Se after partial resection of the small intestine.

Studies of many authors have shown that Se deficiency can cause decreased activity of glutathione peroxidase and lower efficiency of the antioxidative barrier [24, 27, 47]. The results of our study are compatible with the above observations, because examined children with allergy had significantly decreased activity of glutathione peroxidase. Positive Spearman coefficient confirms dependence between Se concentrations and activity of glutathione peroxidase in children with food allergy.

Deficiency of $\mathrm{Zn}$ in children with food allergy can be caused by different factors, similarly to Se. Data presented in the medical literature show that Polish women during pregnancy have lower values of $\mathrm{Zn}$ in comparison to women who are not pregnant. Similarly, they have lower values of this microelement in comparison to women from other countries [37, 42, 44]. It was also confirmed that absorption of $\mathrm{Zn}$ is higher from breast milk. That is why artificial feeding predisposes to $Z n$ deficiency [5, 31, 48, 49]. Among examined patients with food allergy, there were significantly more children artificially fed since birth. A high percentage of children in the first year of life could additionally predispose to lower values of $\mathrm{Zn}$.

In conclusion, in children with allergy decreased concentrations of Se and Zn, and lower values of glutathione peroxidase and superoxide dismutase, which increased after an elimination diet, were affirmed. These observations suggest their role in pathogenesis of food allergy. The conducted observations indicate the need to monitor trace elements content in the diet in children with food allergy. The results showed that children with food allergy had a weakened antioxidative barrier.

\section{References}

1. Fälth-Magnusson K, Kjellman NIM. Allergy prevention by maternal elimination diet during late pregnancy - a 5 year follow up of randomized study. J Allergy Clin Immunol 1992; 89: 709-13.

2. Litov RE, Combs GFJ. Selenium in pediatrics nutrition. Pediatrics 1991; 87: 339-51.

3. Lockitch J, Taylor GP, Wong LT, et al. Cardiomyopathy associated with nonendemic selenium deficiency in a Caucasian adolescent. Am J Clin Nutr 1990; 52: 572-7.

4. Rogala B, Szczerbowski M, Żegleń S, Grzanka A. Selenium concertration in plasma and whole blood in asthmatic patients. Alergia Astma Immunologia 2002; 7: 147-50.

5. Zachara B, Czerwionka-Szaflarska M. Role of selenium in fetal period and in infancy. Post Hig Med Dośw 1994; 48: 471-90.
6. DiSilvestro RA, Blostein-Fujii A. Moderate zinc deficiency in rats enhances lipoprotein oxidation in vitro. Free Rad Biol Med 1997; 22: 739-42.

7. Kamer B, Wąsowicz W, Michalecka J, et al. Chosen elements of antiocidant barrier in infants and small children with disorders of liver cell function. Przegl Ped 1996; (Suppl. 1/3): 320-6.

8. Lunec J. Free radicals: their involment in disease processes. Ann Clin Bioch 1990; 27: 173-9.

9. Malewski W, Krauss H, Ignyś I, Krawczyński M. Oxidative stress and antioxidative factors in gastroentorologic pathology. Ped Prakt 1995; 3: 253-8.

10. Popadiuk S, Korzon M, Wąsowicz W, Gromadzińska J, Skłodowska M, Szarszewski A. Selenium, glutathione peroxidase and TBARS in plasma of children with malignant diseases of the hematopoetic system. Ped Pol 1995; 70: 313-7.

11. Brooks JD, Metter EJ, Chan DW, et al. Plasma selenium level before diagnosis and the risk of prostate cancer development. J Urol 2001; 166: 2034-8.

12. Halliwel B, Gutteridge JMC, Cross CE. Free oxygen radicals, antioxidants and human disease: where are we now? J Lab Clin Med 1992; 119: 598-620.

13. Knekt P, Heliovaara M, Aho K, Alfthan G, Marniemi J, Aromaa A. Serum selenium, serum alpha-tocopherol, and the risk of rheumatoid arthritis. Epidemiology 2000; 11: 402-5.

14. Litonjua AA. Dietary factors and the development of asthma. Immunol Allergy Clin North Am 2008; 28: 603-29.

15. Sackesen C, Ercan H, Dizdar E, et al. A comprehensive evaluation of the enzymatic and nonenzymatic antioxidant systems in childhood asthma. J Allergy Clin Immunol 2008; 122: 78-85.

16. Salim AS. Role of oxygen-derived free radical scavengers in the management of recurrent attacks of ulcerative colitis, a new approach. J Lab Clin Med 1992; 119: 710-7.

17. Kaczmarski M, Korol D, Cudowska B. Chosen epidemiological aspects of allergic diseases in children. Terapia 1998; 5: 3-6.

18. Kamer B, Zielińska W, Raczyńska J, Sobczyńska K. Prevalence of allergic diseases in infants and small children of the Łódź population. Ped Pol 1999; 74: 665-8.

19. Burks AW, Sampson HA. Diagnostic approaches to the patient with suspected food allergies. J Pediatr 1992; 121: 46-71.

20. Krauss H, Ignyś I, Malewski W, et al. Oxidative stress indicators in children with food allergy. Ped Pol 1999; 74: 125-33.

21. Rubin RN, Navon L, Cassano PA. Relationship of serum antioxidants to asthma prevalence in youth. Am J Respir Crit Care Med 2004; 169: 393-8.

22. Bankson DD, Kestin M, Rifai N. Role of free radicals in cancer and atherosclerosis. Clin Lab Med 1993; 13: 463-80.

23. Halliwell B, Chirico S. Lipid peroxidation its mechanisms measurement and significance. Am J Clin Nutr 1993; 57 (5 Suppl.): 715-25.

24. Pokuszyńska K, Brózik H, Sikora JP. The influence of treatment with hypoallergic diet on antioxidative barrier and lipid peroxidation products in children with cow's milk allergy. Alergia Astma Immunologia 2000; 5: 68-73.

25. Sokol RJ, Hoffenberg BJ. Antioxidants in pediatric gastrointestinal disease. Pediatr Clin North Am 1996; 43 : 471-88.

26. Kim JH, Ellwood PE, Asher MI. Diet and asthma: looking back, moving forward. Respiratory Research 2009; 12: 49. 
27. Kalita B, Nowak P, Ślomok M, et al. Selenium plasma concentration level in children with food allergy. Pol Merk Lek 2001; 10: 411-3.

28. Hasselmark L, Malmgren R, Zetterström O, Unge G. Selenium supplementation in intrinsic asthma. Allergy 1993; 48: 30-6.

29. Kadrabová J, Mad'aric A, Kovaciková Z, Podivínsky F, Ginter E, Gazdík F. Selenium status is decreased in patients with intrinsic asthma. Biol Trace Elem Res 1996; 52: 241-8.

30. Fairris GM, Perkins PJ, Lloyd B, Hinks L, Clayton BE. The effect on atopic dermatitis of supplementation with selenium and vitamin E. Acta Derm Venereol 1989; 69: 359-62.

31. Sherman AR. Zinc, copper and iron nutriture and immunity. J Nutr 1992; 122 (3 Suppl): 604-9.

32. Smogorzewska E. Role of zinc in immunologic processes. Ped Pol 1989; 64: 254-8.

33. Yoshika T, Ichikawa I. Cellular defence mechanisms against ischaemic and toxic injury. Nephrol Dial Transplant 1994; 9 (Suppl 4): 34-6.

34. Kjellman NIM, Johansosson SGO, Roth A. Serum IgE levels in healthy children quantifield by a sandwich technique. Clin Allergy 1976; 6: 51-6.

35. Watkinson JH. Fluorometric determination of selenium in biological material with diaminonaphtalene. Anal Chem 1966; 38: 92-7.

36. Paglia DE, Valentine WN. Studies on quantitative and qualitative characterisation of erythrocyte glutathione peroxidase. J Lab Clin Med 1967; 70: 158-69.

37. Wąsowicz W, Kamer B, Krasomski G, Wołkanin P, Gromadzińska J, Raczyńska J. Serum concentrations of selenium, copper, zinc and iron in maternal and placental blood. Mat Nauk Drugiego Polsko-Francuskiego Spotk Ped 1993; 10: 150-3.

38. Floriańczyk B. Trace elements in metabolism of human body. Med Ogólna 1996; 2: 116-24.

39. Hocman G. Chemoprevention of cancer, selenium. Int J Biochem 1988; 20: 123-32.

40. Levander OA. A global view of human selenium nutrition. Ann Rev Nutr 1987; 7: 227-50.

41. Myers DB. Dietary selenium. N Z Med J 1992; 105: 481.

42. Wąsowicz W, Zachara BA. Selenium concentration in blood and urine of a healthy Polish subpopulation. J Clin Chem Clin Biochem 1987; 25: 409-13.

43. Zachara B. Selenium and gluthatione peroxidase in blood of children. Pol Tyg Lek 1983; 38: 909-13.

44. Zachara BA, Wąsowicz W, Gromadzińska J, Skłodowska M, Krasomski G. Glutatione peroxidase activity, selenium and lipid peroxide concentrations in blood from a healthy Polish population. Maternal and Cord Blood. Biol Trace Element Res 1986; 10: 175-87.

45. Aaseth J, Aadland E, Thomassen Y. Serum selenium in patients with short bowel syndrome. In: Selenium in biology and medicine. Combs GF, Spallholz JE, Levander OA, Oldfield JE (eds.). Van Nostrand Reinhold Company, New York 1987.

46. Bratakos MS, loannou PV. Selenium in human milk and dietary selenium intake by Greeks. Sci Total Environ 1991; 105: 101-7.

47. Gromadzińska J, Wąsowicz W, Skłodowska M, Perek D, Popadiuk S. Glutation peroxidase activity, selenium and lipid peroxides levels in blood of cancer children. Ann Clin Res 1988; 20: 177-83.

48. Szotowa W. Role of trace elements in nutrition of children and youth. Przegl Ped 1987; 17: 81-7.

49. Yosodhara P, Ramaraju LA, Raman L. Trace minerals in pregnancy 1. Copper and zinc. Nutr Res 1991; 11: 15-21. 